\title{
EXCESS MOLAR VOLUMES, SURFACE TENSIONS, VISCOCITY DEVIATION AND FTIR SPECTROSCOPY OF 1-BUTANOL-ETHYL ACETATE BINARY SYSTEM MIXTURE
}

\author{
Mustafa J. Nuhma, \\ Chemical Engineering Department, Engineering College, University of Al-Qadisiyah, Al-Qadisiyah, Iraq. \\ E-mail: mustafa.alhamadani@qu.edu.iq
}

Received on 12 November 2017 Accepted on 28 December 2017 Published on 15 March 2018

DOI: $10.30772 /$ qjes.v10i4.511

\begin{abstract}
The physical properties (viscosity, surface tension and density) were computed in laboratory using different laboratory equipment for binary and pure system at $(P=1 \mathrm{~atm}$ and $T=25^{\circ} \mathrm{C}$ ). At mole fraction 0.5 , the excess volume was found to be positive value while the deviation in viscosity and surface tension was found as negative values at the same mole fraction. Experimental excess properties were compared using Redlich-Kister equation and showed acceptable standard deviation. The inter molecular interaction of the 1-Butanol and Ethyl acetate found to be negligible and the vulnerability of the hydrogen bonds according to the FTIR spectra to a mixture of 1-Butanol and Ethyl acetate is consistent with the positive values of excess volume. Overlying the values of surface tension and the deviation in viscosity was found as negative values for all mole fractions studied.
\end{abstract}

Keywords: 1-butanol, Density, Ethyl acetate, Viscosity, FTIR analysis, Excess molar volume, Surface tension and Molecular interaction.

\section{INTRODUCTION}

Many of industrial processes require a large amount of information related to the physical and chemical properties of different types of fluids. Physical and chemical properties, for example, excess properties and intermolecular interactions are very important factors that affect the molecular structure and lead to the non-ideal deviation in the transport phenomena (fluid flow, the mass and heat transfer) [1-5]. Several studies have been carried out to study the excess thermodynamic properties of different types of non-aqueous liquids mixture [6-21]. The importance of thermodynamic excess properties is not only useful for the design and study of transport phenomena, but also for obtaining the appropriate data, which is the basis for the development of new predictive equations and linking them with special relationships. On the other hand, the practical data for the density of the binary liquid mixture was used to calculate the excess volume property related to the intermolecular interactions [22-24]. Anwar discussed changes in the values of excess thermodynamic properties with the change in composition and the temperature and their impact on hydrogen bonds and their effect on the mixing process [25]. Shekaari et al. used the excess properties in studying the polymer's effectiveness and demonstrated increased effectiveness by increasing the molar mass of polymer [26]. From above survey we conclude that 1-Butanol and Ethyl acetate are important solvents and have been used in many industrial processes and there is a need for thermodynamic process data which is the basis for theoretical and design purposes. The current study provides practical and 


\section{AL-QADISIYAH JOURNAL FOR ENGINEERING SCIENCES}

numerical data for the excess molar volume, the surface tension deviation and the viscosity deviation. The Redlich-Kister equation was used for correlation of the practical data. FTIR analysis was obtained and checked for 1-Butanol - Ethyl acetate binary liquid mixture as well as to clarify the excess and the deviation property.

\section{EXPERIMENTAL}

\subsection{MATERIALS AND METHOD}

1-Butanol and Ethyl acetate were obtained from the Fisher scientific (United Kingdom). The binary mixtures were prepared for the experiment using an electronic balance by CPA-225D, Germany, and manufactured by Sartorius. The measured weight accuracy was $\pm 0.01 \mathrm{mg}$. The density is measured using the densometer (Anton bar, DSA5000M, Austria). The calibration of the densometer was performed using degassed distilled water. Ethanol had been used to clean the tube of the vibrator for the densometer. The surface tension properties of the pure and binary of 1-Butanol and Ethyl acetate are determined using a surface tension measuring device (LY-1068 tensometer, China). The accuracy of this device is within range \pm 0.0001 . The capillary viscometer was used to determine the viscosity of the pure and the binary mixture of 1-Butanol and Ethyl acetate. The viscosity was calibrated using distilled water and Ethanol. The accuracy of this device has been determined where it within a value of $\pm 0.028 \mathrm{~m}^{2} . \mathrm{s}-1$. The FTIR spectra of the 1-Butanol and Ethyl acetate liquid system are recorded using Bruker, Tensor II, Germany. The reading clarity of this device was within the $1 \mathrm{~cm}^{-1}$ for the spectrum range between $4000-400 \mathrm{~cm}^{-1}$.

\section{THE RESULTS AND DISCUSSION}

\subsection{THE DENSITY AND EXCESS MOLAR VOLUME}

The densities of pure and mixture for 1-Butanol and Ethyl acetate have been measured in practically and have been tabulated in table (1) and table (2). The measured density was obtained at $25^{\circ} \mathrm{C}$ and at normal pressure. The excess molar volume was calculated according to the following equation and the values were set in table (2).

$$
V^{E}=V_{m}-\sum_{j=1}^{2} x_{i} V_{i} \cdots(1)
$$

Where $\left(V_{m}\right)$ were calculated from the practical values of the mixture density according to equation (2).

$$
V_{m}=\frac{\left[\sum_{i=1}^{2} x_{i}\left(M_{w i}\right)\right]}{\rho} \cdots
$$

\section{Where:}

$\mathrm{V}_{\mathrm{m}}$ : mixture molar volume.

$V_{i}$ : 1-Butanol or Ethyl acetate volume.

Mw: molecular weight of the 1-Butanol or Ethyl acetate. 


\section{AL-QADISIYAH JOURNAL FOR ENGINEERING SCIENCES}

Vol. 10, No. 4

ISSN: $1998-4456$

$\rho:$ density of the mixture volume.

$\mathrm{x}_{\mathrm{i}}$ : mole fraction of the 1-Butanol.

Figure (1) shows the change in molar volume with the molar fraction of 1-Butanol. The nonlinear increase was observed in excess molar volume with increased molar fraction. The non-ideal behavior of the excess molar volume can be due to the interactions and the intermolecular in the binary system of the liquid mix of 1-Butanol and Ethyl acetate, which have been explained by other researches [27]. The positive value of the excess molar volume was obtained for all fractions and the highest value of the molar volume was obtained at the value of the molar fraction 0.3 .

Table 1: Experimental data of surface tension $(\sigma)$, density $(\rho)$ and viscosity $(\mu)$ for pure 1-Butanol and Ethyl acetate at $25^{\circ} \mathrm{C}$.

\begin{tabular}{|c|c|c|c|c|c|}
\hline No. & Substance & M.wt & $\rho$ & $\sigma$ & $\mu$ \\
\hline 1 & 1-Butanol & $74.123 \mathrm{~g} / \mathrm{mol}$ & $\begin{array}{c}0.810 \\
\mathrm{~g} / \mathrm{cm}^{3}\end{array}$ & $\begin{array}{c}24.93 \\
\text { Dyn/cm }\end{array}$ & $\mathrm{Cp}$ \\
\hline 2 & Ethyl acetate & 88.106 & 0.9 & 24 & 0.423 \\
& & $\mathrm{~g} / \mathrm{mol}$ & $\mathrm{g} / \mathrm{cm}^{3}$ & Dyn/cm & $\mathrm{Cp}$ \\
\hline
\end{tabular}

Table 2: Deviation of the surface tension $\left(\delta_{\sigma}\right)$, surface tension $(\sigma)$, density of the mixture $\left(\rho_{\mathrm{m}}\right)$, excess of molar volume $\left(\mathrm{V}^{\mathrm{E}}\right)$, viscosity $\left(\mu_{\mathrm{mix}}\right)$ and deviation of the viscosity $(\delta \mu)$ for the 1-Butanol and Ethyl acetate mixture at standard conditions.

\begin{tabular}{|c|c|c|c|c|c|c|c|}
\hline $\mathrm{X}_{1}$ & $\mathrm{X}_{2}$ & $\rho_{\mathrm{m}}$ & $\mathrm{V}^{\mathrm{E}}$ & $\sigma$ & $\delta_{\sigma}$ & $\mu_{\mathrm{mix}}$ & $\mu$ \\
\hline 0.1 & 0.9 & 0.819 & 0.034 & 23.803 & -0.29 & 0.601 & -0.034 \\
\hline 0.2 & 0.8 & 0.882 & 0.061 & 23.646 & -0.54 & 0.772 & -0.075 \\
\hline 0.3 & 0.7 & 0.873 & 0.079 & 23.599 & -0.68 & 0.970 & -0.089 \\
\hline 0.4 & 0.6 & 0.864 & 0.074 & 23.722 & -0.65 & 1.194 & -0.077 \\
\hline 0.5 & 0.5 & 0.856 & 0.053 & 23.935 & -0.53 & 1.419 & -0.064 \\
\hline 0.6 & 0.4 & 0.847 & 0.028 & 24.188 & -0.37 & 1.643 & -0.052 \\
\hline 0.7 & 0.3 & 0.838 & 0.019 & 24.361 & -0.29 & 1.871 & -0.036 \\
\hline 0.8 & 0.2 & 0.828 & 0.011 & 24.594 & -0.15 & 2.099 & -0.02 \\
\hline 0.9 & 0.1 & 0.819 & 0.004 & 24.777 & -.006 & 2.323 & -0.008 \\
\hline 1 & 0 & 0.81 & 0 & 24.93 & 0 & 2.544 & 0 \\
\hline
\end{tabular}




\section{AL-QADISIYAH JOURNAL FOR ENGINEERING SCIENCES}

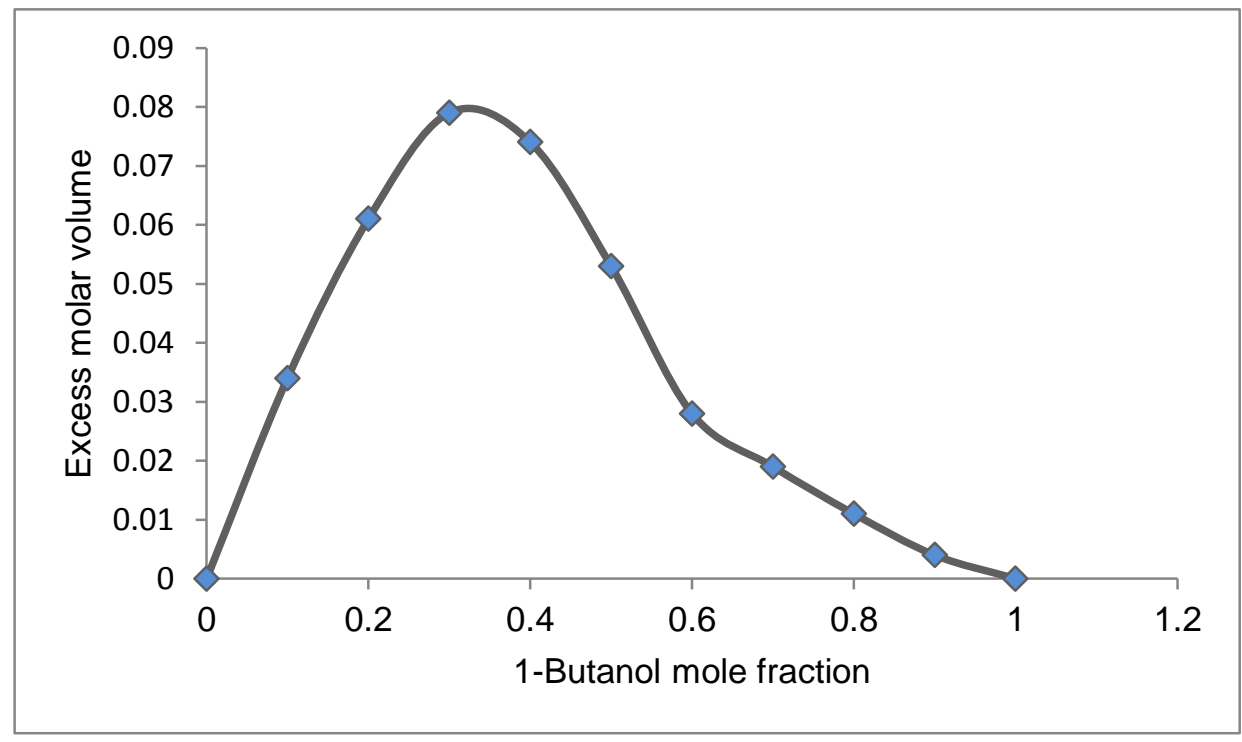

Figure 1: Excess molar volume as a function of 1-Butanol mole fraction for the 1-Butanol-Ethyl acetate binary mixture.

From our results related to the excess molar volume, we can put a mathematical equation showing the change in the values of the excess molar volume with the change of the molar fraction values of this binary mixture:

$$
V^{E}=0.0932 X^{4}+0.8283 X^{3}-1.2984 X^{2}+0.5699 X-0.0038
$$

The equation that was concluded above agreement with the results of study carried out Jiménez et al. [27].

\subsection{SURFACE TENSION DEVIATION}

The values of the deviation in surface tension were calculated from the surface tension practical data and according to the following equation [27]:

$$
\Delta \sigma=\sigma_{m}-\left(x_{1} \sigma_{1}+x_{2} \sigma_{2}\right)
$$

The change in surface tension deviation values with the molar fraction of 1-Butanol is illustrated in figure (2) and is summarized in table (2). The negative behavior in the surface tension deviation values of all the specified molar fraction values is clearly shown. 


\section{AL-QADISIYAH JOURNAL FOR ENGINEERING SCIENCES}

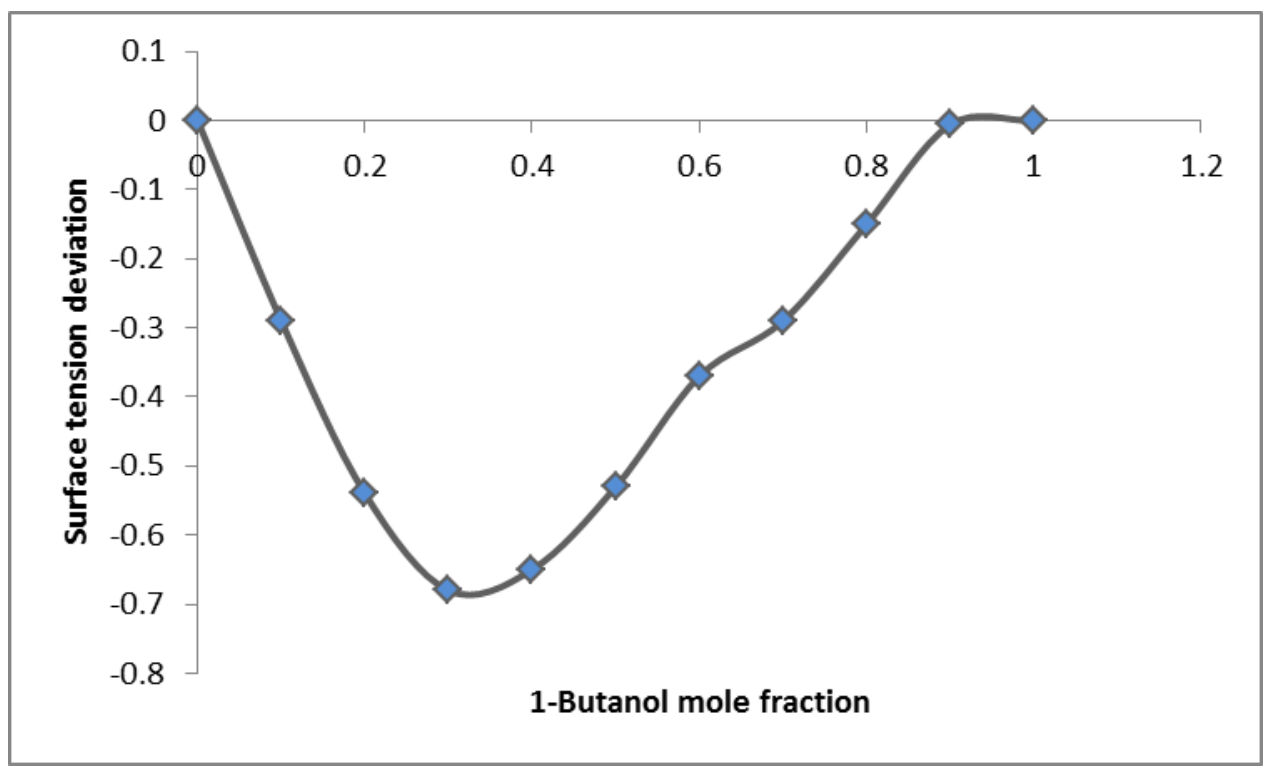

Figure 2: Surface tension deviation as a function of 1-Butanol mole fraction for the 1-Butanol-Ethyl acetate binary mixture.

From our results related to the surface tension deviation, we can put a mathematical equation showing the change in the values of the surface tension deviation with the change of the molar fraction values of this binary mixture:

$$
\delta_{\sigma}=-1.0897 X^{4}-2.3221 X^{3}+7.6295 X^{2}-4.2358 X+0.00184
$$

The equation that was concluded above agreement with the results of study carried out Jiménez et al. [27]

\subsection{VISCOSITY DEVIATION}

The viscosity deviation was computed from the practical data of the viscosity of the pure and the binary mix liquid at the different mole fractions using the following equation [27]:

$$
\Delta \eta=\eta_{m}-\left(x_{1} \eta_{1}+x_{2} \eta_{2}\right) \cdots(4)
$$

The calculated values for the deviation in viscosity were set in table (2) and were illustrated in figure(3). All these values for the deviation of the viscosity are negative values. The lowest value of the deviation in viscosity was at 0.3 molar fraction of 1 -Butanol. 


\section{AL-QADISIYAH JOURNAL FOR \\ ENGINEERING SCIENCES}

Vol. 10, No. 4

ISSN: $1998-4456$

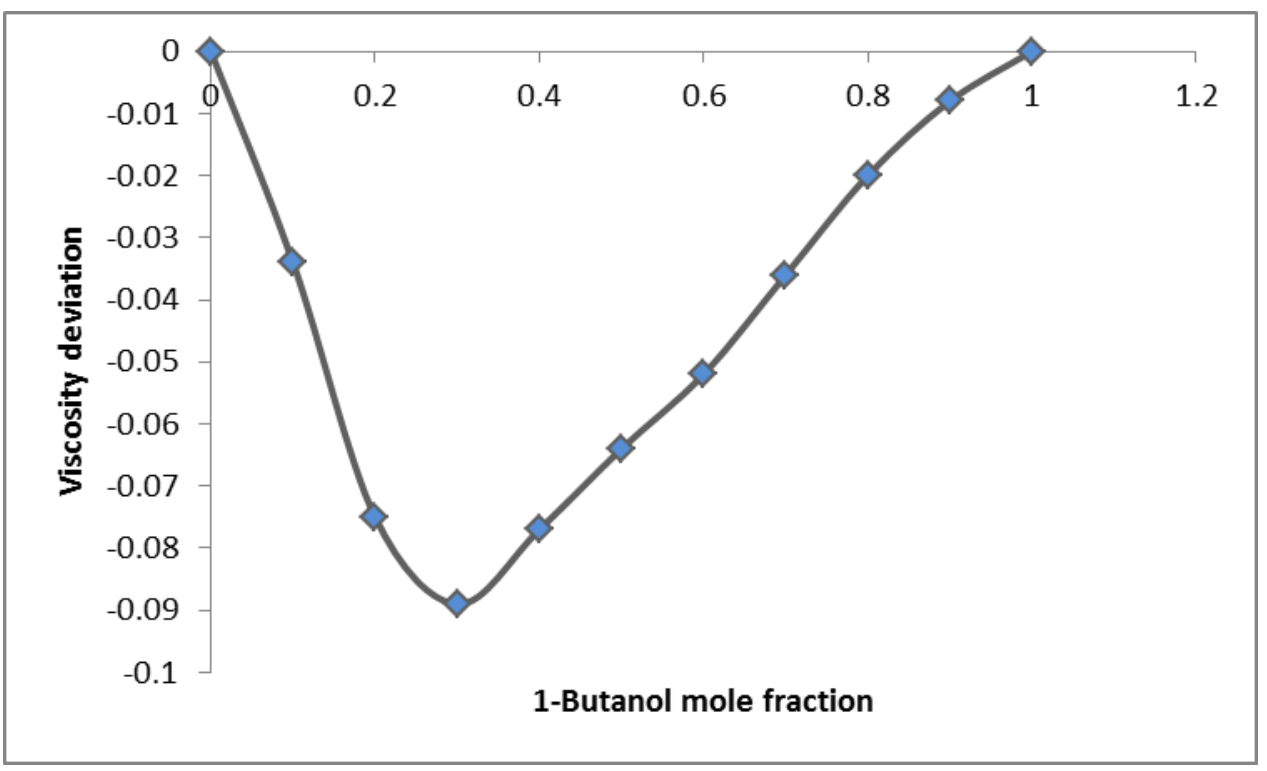

Figure 3: Viscosity deviation as a function of 1-Butanol mole fraction for the 1-Butanol-Ethyl acetate binary mixture.

From our results related to the viscosity deviation, we can put a mathematical equation showing the change in the values of the viscosity deviation with the change of the molar fraction values of this binary mixture:

$$
\mu=0.1369 X^{4}-0.844 X^{3}+1.3054 X^{2}-0.603 X+0.0038
$$

The equation that was concluded above agreement with the results of study carried out Alvarez et al. [28]

\subsection{REDLICH-KISTER CORRELATION}

The values of excess molar volume, surface tension deviation and viscosity deviation were corrected relative to the Redlich-Kister equation as the following [29]:

$$
V^{R E}=X_{1} X_{2} \sum_{i=0}^{2} A_{i}\left(X_{1}-X_{2}\right)^{i} \cdots(5)
$$

Where:

$X_{1}, X_{2}$ : are the mole fraction of 1 -Butanol and Ethyl acetate respectively.

$A_{\mathrm{i}}$ : are the coefficients of the Redlich-Kister equation and tabulated in the table (3).

The standard deviation (SD) of the binary system was computed using equation (6) and the results were tabulated in table (3) [27]. 


\section{AL-QADISIYAH JOURNAL FOR ENGINEERING SCIENCES}

$$
S D=\left(\frac{\sum_{i=1}^{M}\left(F_{e x p}^{E}-F_{\text {cal }}^{E}\right)^{2}}{M-N}\right)^{1 / 2} \cdots(6)
$$

M, N: Are the experimental samples and the constraints number respectively.

The experimental results showed a reasonable deviation from theoretical values as shown in table(3) .

Table 3: The coefficients of Redlich-Kister equation in the case of correlation the excess molar volume $\left(\mathrm{V}^{\mathrm{E}}\right)$, surface tension deviation $\left(\delta_{\sigma}\right)$ and viscosity deviation for the samples of 1 -Butanol-Ethylacetate mixture at

\begin{tabular}{|c|c|c|c|c|c|l|l|}
\hline Function & $\begin{array}{c}\text { Temperature, } \\
{ }^{\circ} \mathrm{C}\end{array}$ & $\mathrm{a}_{0}$ & $\mathrm{a}_{1}$ & $\mathrm{a}_{2}$ & $\mathrm{a}_{3}$ & $\mathrm{a}_{4}$ & $\mathrm{SD}$ \\
\hline $\mathrm{V}^{\mathrm{E}}$ & $25{ }^{\circ} \mathrm{C}$ & -0.0038 & 0.5699 & -1.2984 & 0.8283 & -0.0932 & 0.0004 \\
\hline$\delta_{\sigma}$ & $25{ }^{\circ} \mathrm{C}$ & 0.00184 & -4.2358 & 7.6295 & -2.3221 & -1.0897 & 0.00003 \\
\hline$\delta_{\mu}$ & $25{ }^{\circ} \mathrm{C}$ & 0.0038 & -0.603 & 1.3054 & -0.844 & 0.1369 & 0.0006 \\
\hline
\end{tabular}

\subsection{FTIR AND INTERMOLECULAR INTERACTION}

FTIR spectroscopy analysis is an effective and very important analysis of the properties of polar chemicals and can be used to regulate functional group and molecular interaction [30]. In the figure (4) below, the FTIR analysis of the 1-Butanol-Ethyl acetate mixture was developed. The FTIR spectra for a mixture of 1-Butanol - Ethyl acetate at different mole fractions showed a very important behavior for hydrogen bonds and demonstrated the non-ideal behavior and deviation in the thermodynamic properties as explained in the previous sections. As seen in the FTIR, the amplitude of the hydrogen top indicates the effect of the intermolecular interaction and the sharpness due to obvious the intermolecular interaction as well. For the pure 1-Butanol, the spectra shows a broad O-H stretch at $3350 \mathrm{~cm}^{-1}$ while the most important peak in the pure Ethyl acetate showed a strong $\mathrm{C}=\mathrm{O}$ peak at $1750 \mathrm{~cm}^{-1}$. While, for the 1-Butanol - Ethyl acetate mixture, the increase in molar fraction caused a weak displacement in the place of the $\mathrm{C}=\mathrm{O}$ peak to a maximum wave number. The effect of hydrogen bonding is weak for the current mixture and has led to weakness intermolecular interaction between 1-Butanol and Ethyl acetate. The result of the FTIR spectrum is consistent with the result of the excess volume and the conclusions were clarified by other researchers [31]. The physical effect mainly involves non - qualitative physical correlations, breaking down the hydrogen bonds in the molecules themselves, weaker dipole - dipole interaction, and interstitial accommodation due to different the molar volumes and the free volumes between undesirable molecules, producing in positive 


\section{AL-QADISIYAH JOURNAL FOR ENGINEERING SCIENCES}

excess molar volume values. The chemical and the structural-geometrical effects was created due to the specific interactions such as forming of hydrogen bonds, charge - transfer (donor- acceptor) complexes, strong dipole-dipole interactions, differences in the size, shape of the component molecules, and making a negative volume excess values [32 - 35]. The concentration based thermophysical properties denotes that the deviation from the ideal behavior of the mixtures and to be provided an indication of the interactions between unlike components in the mixtures.

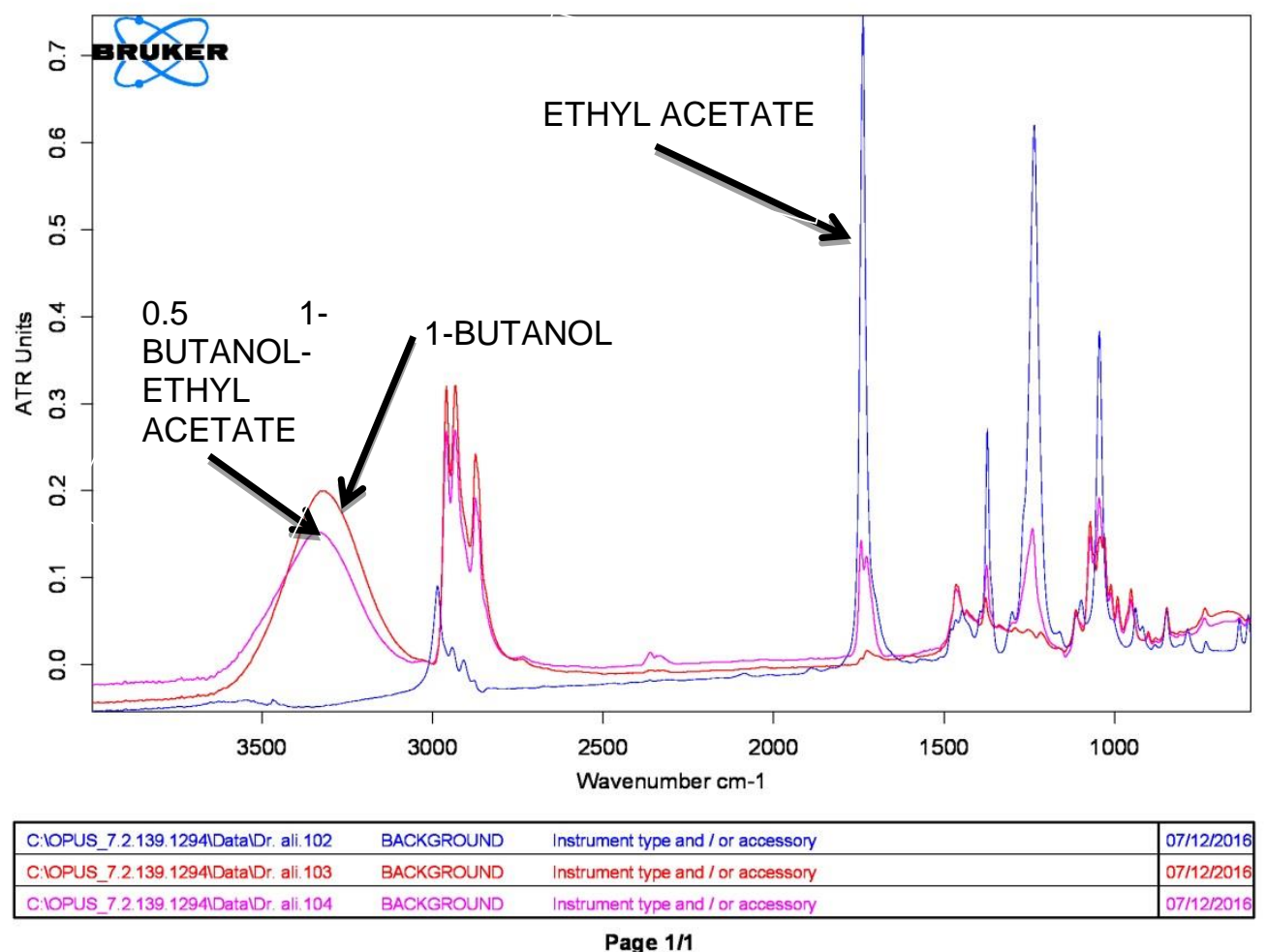

Figure 4: FTIR Spectra of 1-Butanol, ethyl acetate and binary mixture of 0.5-0.5 1-Butanol-Ethylacetate at Temperature $=25^{\circ} \mathrm{C}$ and Pressure $=1$ atm .

\section{CONCLUSIONS}

1-The practical result of excess volume, surface tension deviation and viscosity deviation showed a nonideal behavior with changing in molar fraction.

2. The correction of excess properties using the Redlich-Kister equation showed an acceptable deviation from the practical results. 


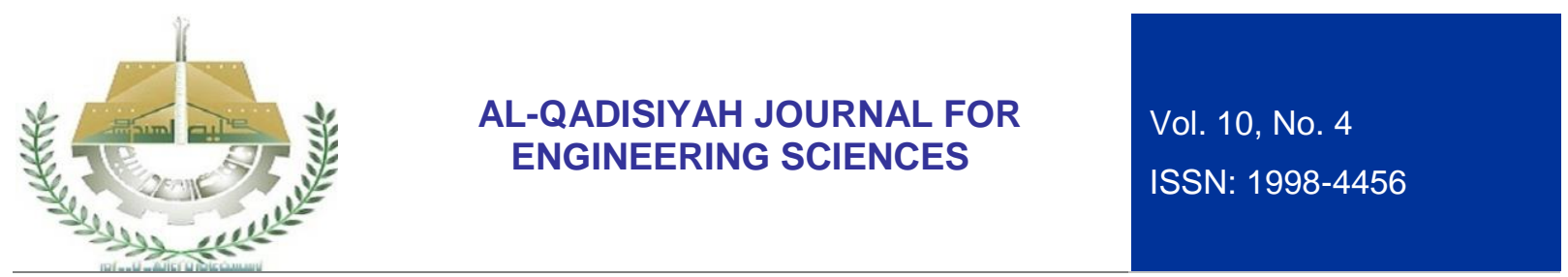

3. The result of the FTIR showed compatibility with the result of excess volume and demonstrated internal hydrogen bonds between 1-Butanol and Ethyl acetate was weak for the mixture and can be concluded that there is a weakness in the place of the upper $\mathrm{C}=\mathrm{O}$ peak of the highest wave number.

4. Determination of excess thermodynamic properties and refractive index of other mixing systems not previously addressed.

\section{REFERENCES}

1. Naessems RM, Clará RA, Marigliano AC., Density, viscosity, excess molar volume and viscosity deviation for [chloroform (1)+ methanol (3)] binary system and [chloroform (1)+ di-isopropylether (2)+ methanol (3)] ternary system at 298.15 K. Chemical Data Collections. 2017 Mar 31;7:68-79.

2. Krakowiak J, Śmiechowski M. , Excess molar volume and viscosity deviation for binary mixtures of $\gamma$ butyrolactone with dimethyl sulfoxide. The Journal of Chemical Thermodynamics. 2017 Jul 31;110:57-64.

3. Ponomareva VG, Lavrova GV. , Effect of the excess protons on the electrotansport, structural and thermodynamic properties of CsH 2 PO 4. Solid State lonics. 2017 Jun 30;304:90-5.

4. Gupta, H., Solanki, S., \& Sharma, V. K. (2017). Topological analysis of thermodynamic properties of binary mixtures containing 1-butyl-3-methylimidazolium tetrafluoroborate and cycloalkanones. Journal of Thermal Analysis and Calorimetry, 127(3), 2459-2472.

5. Zheng P, Cai D, Zhao J, Shen W. , Thermodynamic properties of mixed surfactants of dodecyltrimethylammonium bromide and 1-dodecyl-3-methylimidazolium bromide. The Journal of Chemical Thermodynamics. 2016 Oct 26.

6. Abdussalam AA, Radović IR, Ivaniš GR, Kijevčanin ML. , High pressure densities and derived thermodynamic properties for the ( $\mathrm{n}$-heptane+n-octane+ ethanol) ternary system. The Journal of Chemical Thermodynamics. 2017 Jun 30;109:91-9.

7. González-Salgado D, Zemánková K, Troncoso J, Romaní L. , Volumetric and thermal excess properties of the $\{(1,2$-dichloroethane or 1, 4-dichlorobutane $)+\mathrm{n}$-dodecane systems $\}$. The Journal of Chemical Thermodynamics. 2017 Apr 3.

8. Malcolm GN, Rowlinson JS. , The thermodynamic properties of aqueous solutions of polyethylene glycol, polypropylene glycol and dioxane. Transactions of the Faraday Society. 1957;53:921-31.

9. Warmińska D, Krakowiak J, Grzybkowski W. , Thermodynamic properties of inorganic salts in nonaqueous solvents. I. Apparent molar volumes and compressibilities of divalent transition-metal perchlorates in N, N-dimethylformamide. Journal of Chemical \& Engineering Data. 2005 Jan 13;50(1):221-5.

10. Jouyban A, Abbasi M, Rahimpour E, Barzegar-Jalali M, Vaez-Gharamaleki J. , Deferiprone solubility in some non-aqueous mono-solvents at different temperatures: experimental data and thermodynamic modelling. Physics and Chemistry of Liquids. 2017 Aug 27:1-8.

11. Shekaari H, Zafarani-Moattar MT, Mokhtarpour M. , Solubility, volumetric and compressibility properties of acetaminophen in some aqueous solutions of choline based deep eutectic solvents at $\mathrm{T}=(288.15$ to 318.15) K. European Journal of Pharmaceutical Sciences. 2017 Nov 15;109:121-30.

12. Kan Z, Malik MA, Al-Thabaiti SA, Alsehri A, Nabi F., Micellization and Thermodynamic Properties of Cationic Surfactant Cetyltrimethylammonium Bromide in non-Aqueous Mixture of Lauric Acid. J. Electrochem. Sci. 2017 May 1;12:4528-42.

13. Marium M, Auni A, Rahman MM, Mollah MY, Susan MA., Molecular level interactions between 1ethyl-3-methylimidazolium methanesulphonate and water: Study of physicochemical properties with variation of temperature. Journal of Molecular Liquids. 2017 Jan 31;225:621-30.

14. Khattab IS, Bandarkar F, Khoubnasabjafari M, Jouyban A., Density, viscosity, surface tension, and molar volume of propylene glycol+ water mixtures from 293 to $323 \mathrm{~K}$ and correlations by the Jouyban-Acree model. Arabian Journal of Chemistry. 2012 Aug 1.

15. Krakowiak J, Śmiechowski M. , Excess molar volume and viscosity deviation for binary mixtures of $\mathrm{Y}^{-}$ butyrolactone with dimethyl sulfoxide. The Journal of Chemical Thermodynamics. 2017 Jul 31;110:57-64. 


\section{AL-QADISIYAH JOURNAL FOR ENGINEERING SCIENCES}

16. Huber ML, Huber ML., Preliminary Models for Viscosity, Thermal Conductivity, and Surface Tension of Pure Fluid Constituents of Selected Diesel Surrogate Fuels. US Department of Commerce, National Institute of Standards and Technology; 2017 Jan 5.

17. Luning Prak DJ., Correction to "Density, Viscosity, Speed of Sound, Bulk Modulus, Surface Tension, and Flash Point of Binary Mixtures of Butylcyclohexane+ Toluene or+ n-Hexadecane". Journal of Chemical \& Engineering Data. 2017 Jul 20;62(8):2473-4.

18. Mussari L, Canzonieri S, Mariano A. , Surface tension and density of the binary mixtures toluene+ methyl propanoate, toluene+ methyl pentanoate, toluene+ methyl heptanoate and toluene+ methyl octanoate at atmospheric pressure and 288.15, 298.15 and 308.15 K. Chemical Data Collections. 2017 Aug 31;9:12533.

19. Zhao J, Wu J, Dai Y, Cheng X, Sun H, Guo Y, Fang W. , Density, Viscosity, and Freezing Point for Four Binary Systems of n-Dodecane or Methylcyclohexane Mixed with 1-Heptanol or Cyclohexylmethanol. Journal of Chemical \& Engineering Data. 2017 Jan 27;62(2):643-52.

20. Lee KH, Park SJ. , Isothermal vapor-liquid equilibria, excess molar volume and the deviation of refractive indices for binary mixtures of 1-butanol, 1-hexanol, 3-methyl-1-butanol and butyl acetate. Fluid Phase Equilibria. 2017 Mar 25;436:47-54.

21. Rezaei-Sameti M, Rakhshi M. , Excess thermodynamic parameters for binary and ternary mixtures of $\{1$-butanol (1)+ cyclohexylamine (2)+ n-heptane (3)\} at different temperatures: A theoretical study. Arabian Journal of Chemistry. 2012 Nov 23.

22. Fang D, Meng X, Wu J. , Compressed Liquid Densities of Binary Mixtures of 1-Butanol and Diethylene Glycol Dimethyl Ether from (283 to 363) K at Pressures up to $100 \mathrm{MPa}$. Journal of Chemical \& Engineering Data. 2017 Jun 27;62(9):2937-43.

23. Alavianmehr MM, Hemmati N, Ghodrati H. , Excess molar volumes, excess thermal expansion coefficients and isentropic compressibility deviations for binary mixtures of benzyl alcohol+(1-butanol, 2butanol, 2-methyl-1-butanol and tert-butanol) at $\mathrm{T}=(298.15-328.15) \mathrm{K}$ and ambient pressure. Physics and Chemistry of Liquids. 2017 Jan 2;55(1):85-99.

24. Anwar N. , Effect of composition and temperature variations on thermophysical properties of binary and ternary mixtures of 1-ethyl-3-methylimidazolium ethylsulfate with 1-butanol and/or methanol. Fluid Phase Equilibria. 2017 Apr 15;437:127-39.

25. Shekaari H, Zafarani-Moattar MT, Faraji S. , Measurement and Correlation of Activity, Density, and Speed of Sound for Binary Mixtures of 1-Propanol+ Poly (Propylene Glycol) 400, 725, and 1025. Journal of Chemical \& Engineering Data. 2017 Nov 2.

26. Jiménez E, Casas H, Segade L, Franjo C. , Surface tensions, refractive indexes and excess molar volumes of hexane+ 1-alkanol mixtures at $298.15 \mathrm{~K}$. Journal of Chemical \& Engineering Data. 2000 Sep 14;45(5):862-6.

27. Álvarez E, Cancela Á, Maceiras R, Navaza JM, Táboas R. , Density, viscosity, excess molar volume, and viscosity deviation of three amyl alcohols+ ethanol binary mixtures from 293.15 to $323.15 \mathrm{~K}$. Journal of Chemical \& Engineering Data. 2006 May 11;51(3):940-5.

28. Redlich O, Kister AT. , Algebraic representation of thermodynamic properties and the classification of solutions. Industrial \& Engineering Chemistry. 1948 Feb;40(2):345-8.

29. Wei Q, Guo X, Wang Y, Yang H. ,Temperature-dependent FTIR study on three kinds of hydrogenbonded benzoic acid dimers in their melt states. Journal of Molecular Liquids. 2013 Jan 31;177:225-8.

30. Hasan M, Hiray AP, Kadam UB, Shirude DF, Kurhe KJ, Sawant AB. , Densities, viscosities, speeds of sound, FT-IR and 1H-NMR studies of binary mixtures of n-butyl acetate with ethanol, propan-1-ol, butan-1-ol and pentan-1-ol at 298.15, 303.15, 308.15 and $313.15 \mathrm{~K}$. Journal of solution chemistry. 2011 Mar 1;40(3):415-29.

31. Sreenivasulu K, Govinda V, Venkateswarlu P, Sivakumar K. , Thermodynamic properties of nonelectrolyte solutions. Journal of Thermal Analysis and Calorimetry. 2014 Feb 1;115(2):1805-11.

32. Sastry NV, Valand MK. , Viscosities and densities for heptane+1-pentanol,+1-hexanol, +1 -heptanol, + 1-octanol,+ 1-decanol, and+1-dodecanol at $298.15 \mathrm{~K}$ and $308.15 \mathrm{~K}$. Journal of Chemical \& Engineering Data. 1996 Nov 12;41(6):1426-8. 


\section{AL-QADISIYAH JOURNAL FOR ENGINEERING SCIENCES}

Vol. 10 , No. 4

ISSN: $1998-4456$

33. Govinda V, Reddy PM, Bahadur I, Attri P, Venkatesu P, Venkateswarlu P. , Effect of anion variation on the thermophysical properties of triethylammonium based protic ionic liquids with polar solvent. Thermochimica acta. 2013 Mar 20;556:75-88.

34. Matos JS, Trenzado JL, González E. , Alcalde R. Volumetric properties and viscosities of the methyl butanoate+ n-heptane+ n-octane ternary system and its binary constituents in the temperature range from 283.15 to 313.15 K. Fluid Phase Equilibria. 2001 Aug 1;186(1):207-34. 